\title{
ECTD Telephone Number Type Terminology
}

National Cancer Institute

\section{Source}

National Cancer Institute. eCTD Telephone Number Type Terminology. NCI Thesaurus.

Code C97192.

Terminology developed to support eCT D Telephone Number Types. 